\title{
Patient Values and Preferences for End-of-Life Treatments: Are Values Better Predictors Than a Living Will?
}

\author{
Laraine Winter, PhD
}

\begin{abstract}
Background: Advance care planning is widely considered important for good treatment decision making. Patient values have been proposed as superior to standard living wills as guides to end-of-life (EOL) care decisions on behalf of decisionally incapacitated patients. Little research has examined whether values outperform living wills as predictors of treatment preferences.

Objective: The study aimed to test whether patient values are associated with treatment preferences, compare values and preferences to responses from a standard living will, and determine whether some values are better predictors than others.

Design: Community-dwelling elderly men and women $(n=304)$ were interviewed in their homes by telephone. The interview consisted of an eight-item EOL values scale, a standard living will question, preferences for four life-prolonging treatments in each of six scenarios, and sociodemographic questions.

Results: Principal components analysis of the EOL values revealed two factors: (1) dignity, pain management, and reluctance to burden others; and (2) religiosity and desire for longevity and following family wishes. In regression analyses, stronger preferences for life-prolonging treatments were correlated with higher scores on factor 1 and lower scores on factor 2. But when living will responses were also entered into the regression model, only religiosity, longevity, and following family wishes predicted treatment preferences independently of the living will responses. Conclusions: Providing better guidance than a living will in determining a patient's EOL treatment preferences are (1) knowledge about a patient's religiosity, (2) patient's wishes for longevity, and (3) patient's wishes for following family preferences. Wishes for dignity and pain management and reluctance to burden others do not offer better guidance than a living will.
\end{abstract}

\section{Introduction}

S INCE THE PASSAge of the Patient Self-determination Act, ${ }^{1}$ much evidence has documented the shortcomings of advance directives (i.e., living wills and durable powers of attorney for health care). They are sometimes unavailable when needed; patients and families do not always wish to follow the decisions recorded in a living will even when it is available; $;^{2-5}$ and some people do not complete them, although increasing numbers do. ${ }^{4-5}$ The standard living will presents an unrealistically clear cut set of circumstances (e.g., a state of permanent unconsciousness) that may not correspond well to actual end-of-life (EOL) scenarios, making it a poor guide for real-life circumstances. ${ }^{6}$ The assumption that the patient's prognosis will be known and communicated frankly to decision makers, a premise of the living will, is dubious. ${ }^{7}$ And patients' wishes for treatment may change after the living will is completed, especially if their health has declined. ${ }^{8-9}$
Some have argued that patients' values are the best predictors of their preferences for medical care at the end of life, better than a standard living will. ${ }^{10-11}$ Such values (e.g., avoiding pain or suffering, quality of life, dignity, selfperceived burden to family, religious beliefs ${ }^{15-18}$ ) have been identified as important considerations that patients and surrogate decision makers apply in making treatment decisions or choosing goals of care. ${ }^{19}$ Much research has explored patients' values, and several values-based planning documents have been developed. ${ }^{12-14}$ But the superiority of patient values over conventional living wills depends upon how well such values empirically predict treatment preferences. That patients can express their values does not guarantee that these values correlate with their treatment preferences. If they are predictive of treatment preferences, are patient values more predictive than a standard living will? And are some values better predictors of treatment preferences than others? Systematic research on the empirical utility of such patient values 
in predicting desired medical treatments typically offered at the end of life (e.g., tube feeding) has been sparse.

A rich source of EOL values is the literature on the characteristics of a good death. The notion of what constitutes a good death varies among individuals, by groups (e.g., patients versus health care providers), and across historical epochs. ${ }^{20}$ Modern views on the features of a good death have been extensively explored by Steinhauser and her colleagues ${ }^{21-22}$ using interviews; focus groups; and quantitative research with patients, families, physicians, and health care providers. This research has identified several broad themes and numerous individual values and has informed the construction of scales to assess the quality of death and dying, like the Quality of Life at the End of Life (QUAL-E) Scale ${ }^{23}$ and the Quality of Dying and Death (QODD) Questionnaire. ${ }^{24}$ But items in these scales, which were not designed as EOL values scales or for advance care planning, have mixed levels of relevance to medical decision making. For example, the wish to follow the teachings of one's religion would seem to have clear application if one's religion dictates the acceptance of all efforts to sustain life. Other values, such as wishes to be treated as a whole person, for connectedness, or for transcendence, are less predictive of a particular treatment preference or goal of care and therefore can be expected to offer little guidance for proxy decision makers. Thus, the research on the characteristics of a good death offers patient values of mixed applicability for predicting preferences for treatments or goals of care for incapacitated patients.

Doukas and his associates ${ }^{25-26}$ developed an EOL values scale and also investigated the empirical association between patient values and treatment preferences, posing two questions: Are such values predictive of treatments preferences? and Are some values more predictive than others? Their values history has three underlying factors: communication, family burden, and physician compliance. But only one factor, self-perceived family burden (the sense that one has become a burden to others), was empirically associated with prefer- ences for medical treatments, with greater concern about burdening family members predicting weaker preferences for aggressive treatment. This value has been identified elsewhere as a major concern of seriously ill patients, with implications for treatment preferences. ${ }^{27-28}$ By contrast, Doukas and colleagues' communication and physician compliance factors were not empirically associated with medical preferences. "To have my wishes followed if unable to speak" or "To have a supportive physician" seem to provide little specific guidance regarding patients' treatment wishes and in fact were not associated with actual wishes for care.

In compiling an EOL values scale we drew on existing scales and the literature on the characteristics of a good death, selecting only items with clear conceptual relevance to either a goal of care or particular medical treatments. Eight values were chosen: wishes to (1) follow one's religious or spiritual beliefs; (2) have a dignified death; (3) be spared pain; (4) avoid burdening family and friends emotionally; (5) avoid burdening others financially; (6) avoid being dependent on others; (7) consider other family members' preferences for your care; and (8) live as long as possible. Our research posed three questions: (1) To what extent are such values associated with preferences for treatments in specific EOL clinical scenarios? (2) To what extent are these values better predictors of treatment preferences than responses to a standard living will question would be? (3) Are some values better predictors of treatments than others?

\section{Methods \\ Subjects}

Men and women 60 years of age or older in the Philadelphia metropolitan region $(n=304)$ were recruited through a variety of sources, including display ads in newspapers, fliers placed in mailboxes in senior housing facilities, mailings from a family medicine practice, and senior centers. Table 1 presents characteristics of the sample. Participants' mean age was

Table 1. Sociodemographic Characteristics of SAmple

\begin{tabular}{|c|c|c|c|c|}
\hline & Percent & Mean (SD) & Actual range & Theoretical range \\
\hline Age & & $72.4(8.0)$ & $60-96$ & - \\
\hline Gender ( $\%$ female) & 77.0 & & & \\
\hline Race (\% nonwhite) & 37.6 & & & \\
\hline \multicolumn{5}{|l|}{ Religious affiliation } \\
\hline Protestant & 42.4 & & & \\
\hline Catholic & 24.7 & & & \\
\hline Jewish & 24.0 & & & \\
\hline None/other & 8.9 & & & \\
\hline \multicolumn{5}{|l|}{ Education } \\
\hline High school or less & 10.5 & & & \\
\hline High school or GED diploma & 26.6 & & & \\
\hline College graduate or higher & 62.9 & & & \\
\hline Marital status (\% married) & 28.9 & & & \\
\hline Financial difficulty ${ }^{\mathrm{a}}$ & & $1.30(1.0)$ & $0-3$ & $0-3$ \\
\hline Physical functioning & & $1.17(0.24)$ & $1.0-2.5$ & $1-3$ \\
\hline Religiosity scale score & & $2.15(1.08)$ & $1-4$ & $1-4$ \\
\hline MMSE score & & $20.54(1.39)$ & $17-22$ & $0-22$ \\
\hline CES-D score & & $5.0(4.6)$ & $0-22.0$ & $0-30$ \\
\hline
\end{tabular}

${ }^{\text {a}}$ Financial well-being scale measures difficulty paying for basics like food, housing, medical care, etc. Scale from 0 (not at all difficult) to 3 (extremely difficult). The mean value represents "somewhat difficult."

CES-D, Center for Epidemiological Studies Depression; MMSE, Mini-Mental State Exam. 
approximately 72 , and $77 \%$ were female. Nearly $63 \%$ had attended college, graduated, or received higher education, indicating a relatively well educated sample. Protestants constituted the plurality. Mean financial difficulty score indicated that paying for basics was "somewhat difficult." Overall, participants were quite religious and relatively high functioning, not depressed, and cognitively intact.

\section{Procedures}

People interested in the study called the research office or completed and returned a stamped self-addressed postcard and were contacted by telephone. A trained interviewer explained the study fully and confirmed the individual's eligibility and willingness to participate. Informed consent was elicited using an institutional review board approved verbal consent script. The 30-minute interview was conducted immediately on the telephone or scheduled for a later time. Participants were offered a \$20 honorarium as thanks for their participation.

\section{Measures}

Treatment preferences. Treatment preferences were operationalized by a set of questions about preferences for four life-prolonging treatments, antibiotics, gall bladder surgery, cardiopulmonary resuscitation (CPR), and tube feeing, in seven medical scenarios. The first scenario was "if you could return to your current health after treatment." The other six described hypothetical poor-health scenarios that varied in cognitive impairment, physical impairment, and presence or absence of pain. The treatments and most of the scenarios were taken from the Life Support Preferences Questionnaire. ${ }^{29}$ Appendix A presents descriptions of the four treatments, the seven scenarios, and a sample question. Participants responded to each question on a scale from 0 (definitely do not want) to 4 (definitely want). Not applicable (NA) and Refused to answer (Refused) were also response options.

Living will question. Each participant was asked, "Would you direct your physician to withhold or withdraw life-sustaining treatment that serves only to prolong the process of dying, if you should be in a terminal condition or in a state of permanent unconsciousness?" Possible responses were "yes" (would not want life-sustaining treatment), "no" (would want life-sustaining treatment), or "I don't know."

End-of-life values scale. This scale comprised eight values relevant to EOL care treatments or goals of care (see Table 2 and Appendix B). Instructions were as follows: "I have some questions about things you may think about in relation to treatment decisions. I will ask about several types of things that people often consider and ask you to rate how important each one is in your thinking." Participants responded to each item on a scale from 0 (not at all important) to 5 (extremely important).

Sociodemographic characteristics. The questionnaire included questions about age, gender, race, years of education, financial difficulty, and marital status.

Physical functioning. This was operationalized as number of deficits in six activities of daily living ${ }^{30}$ (ADL)getting around the house, eating, dressing, grooming, bathing, and using the toilet-and eight instrumental activities of
TABle 2. Factors Derived from the EOL Values Scale and Constituent Items

\begin{tabular}{lccc}
\hline Factor/items & $\begin{array}{c}\text { Cronbach's } \\
\alpha\end{array}$ & $\begin{array}{c}\text { Percent } \\
\text { variance }\end{array}$ & $\begin{array}{c}\text { Factor } \\
\text { loading }\end{array}$ \\
\hline $\begin{array}{l}\text { Avoidance of burden } \\
\text { and pain/dignity }\end{array}$ & .69 & 32.430 & \\
$\begin{array}{l}\text { Wish to avoid burdening } \\
\text { others emotionally }\end{array}$ & & .818 \\
$\begin{array}{l}\text { Wish to avoid dependence } \\
\text { on others }\end{array}$ & & .808 \\
$\begin{array}{l}\text { Wish to avoid burdening } \\
\text { others financially }\end{array}$ & & .767 \\
$\begin{array}{l}\text { Wish for a dignified death } \\
\text { Wish to be spared pain }\end{array}$ & & .515 \\
$\begin{array}{l}\text { Longevity/family } \\
\text { wishes/religiosity }\end{array}$ & .60 & 20.031 & .401 \\
$\begin{array}{l}\text { Wish to live as long } \\
\quad \text { as possible }\end{array}$ & & .760 \\
$\begin{array}{l}\text { Wish to follow } \\
\text { family's preferences }\end{array}$ & & .734 \\
$\begin{array}{l}\text { Wish to follow } \\
\text { religious teachings }\end{array}$ & & .707 \\
\hline
\end{tabular}

daily living ${ }^{31}$ (IADL) — using the phone, shopping for groceries, preparing meals, doing housework or tidying up, doing laundry, taking medicine, managing money, and getting to places out of walking distance. Dependence on each activity was rated on three-point scales $(1=$ need no help, 2 =need some help, $3=$ need complete help). Summing across the 14 activities yielded a theoretical or possible range from 14 to 42 , with 42 indicating help needed on every activity and 14, no help needed on any activity.

Mood. The 10-item version of the Center for Epidemiological Studies Depression (CES-D) Scale was used to assess mood. ${ }^{33}$ Participants responded to each question on a fourpoint scale from 0 (rarely or some of the time) to 3 (most or almost all of the time). Scores were summed to represent depressed mood. Possible scores, therefore, ranged from 0 to 30.

Cognitive status. Cognitive status was assessed using a telephone version of the Mini-Mental State Exam (MMSE), ${ }^{33}$ which excludes items that must be administered face to face. Possible scores range from 0 to 23 , with 23 indicating no errors. All participants scored 17 or higher (see Table 1).

\section{Data analysis}

End-of-life values: factor analysis. Factor analysis refers to a broad group of mathematical procedures for determining which variables belong to which groups. ${ }^{34}$ To identify groups of variables underlying the eight EOL values, the principal-components method of factor analysis was used. This method represents the optimal factor analytic approach, because by maximizing the sum of squared loadings of each factor extracted, each principal-component factor explains more variance than would the loadings obtained from any other method of factoring. Varimax rotation was used to extract orthogonal factors. This analysis revealed two orthogonal factors with eigenvalues greater than 1. Factor 1 loaded avoiding burden to others, avoiding dependence on others, wishes for dignity, and pain management. Factor 2 loaded 
wishes for following family preferences and the teachings of one's religion and for longevity (i.e., to live as long as possible). Cronbach's alpha for each subscale was computed. Table 2 presents the two factors, including alphas, percent of variance explained, constituent items, and factor loading of each item. Means for each factor were computed to operationalize the two EOL values and served as independent variables in subsequent analyses.

Living will responses. Given that the living will question was, "Would you instruct your physician to withhold/ withdraw life-prolonging treatment...?" "I don't know" responses were grouped with the "no" group, following the reasoning that a patient who responded "I don't know" would receive aggressive treatment, given the default option for EOL treatment in the United States is for more aggressive, lifeprolonging treatment. ${ }^{35}$ Thus, responses to the living will question were accordingly dichotomized into withhold life-prolonging treatment ("yes") or don't withhold life-prolonging treatment ("no").

Selection of covariates. To select covariates for subsequent analyses, mean preference for life-prolonging treatment across all treatments and scenarios was examined in relation to sociodemographic covariates (race, age, gender, and financial difficulty). We conducted Pearson product moment correlations or $t$ tests, as appropriate.

Associations of EOL values to four treatment preferences in seven scenarios. A repeated-measures analysis of covariance was computed, with repeated measures on the seven health scenarios and four treatments. The two EOL values factors were the independent variables and demographic variables served as covariates. Post hoc multiple regression (MR) analyses were conducted on treatment preferences for each scenario, entering demographic variables and the two EOL value factors on block 1 and adding the living will responses on block 2 . This permitted us to determine whether the EOL values contributed to the prediction of treatment preferences over and above living will responses. All analyses were conducted using SPSS 17.0 (SPSS Inc., Chicago, IL).

\section{Results}

Results of the study consist of the relation of EOL values to preferences for four life-prolonging treatments in seven scenarios. Mean treatment preferences were associated with age $(p=.011)$, race $(p<.0001)$, gender $(p=.050)$, and financial difficulty $(p<.0001)$. Therefore, subsequent analyses were adjusted for these variables.

The seven (scenarios) by four (treatment types) repeatedmeasures ANCOVA revealed a main effect for scenario (F [6, $284]=3.920, p=.001)$ but not for treatment type $(\mathrm{F}[3,287]=0.596$, $p=.618)$, and no interaction between scenario and treatment type $(\mathrm{F}[18,272]=0.609, p=.890)$. Therefore, mean treatment preferences were calculated for each of the seven scenarios across the four treatment types and these seven means were used as dependent variables in the subsequent MR analyses.

In block 1 of the MRs, stronger religiosity/longevity/family wishes values (Factor 2) were associated with preferences for more life-prolonging treatments, with significant associations for all seven scenarios (see Table 2). Conversely, stronger dignity/pain management/avoidance of burden values were associated with weaker preferences for life-prolonging treatment. This association was statistically significant in all scenarios except the best-case and worst-case scenarios, "as you are now" and severe stroke with coma. These associations were independent of the sociodemographic characteristics.

In block 2 of the MRs, responses to the living will question were associated in the expected direction with preferences for life-prolonging treatment, i.e., "yes" responses (the patient would direct the physician to withhold/withdraw life-prolonging treatment) were associated with lower preferences for such life-prolonging treatment, attaining significance in five scenarios. With the living will responses included in block 2 of the model, the religiosity/longevity/ family wishes values remained significantly associated with stronger preferences for life-prolonging treatments in all seven scenarios. By contrast, stronger dignity/pain management/ avoidance of burden values were associated with weaker preferences only in the two cancer scenarios. Table 3 presents these MR results. Because findings for the sociodemographic

Table 3. Life-Prolonging Treatment Preferences in Seven Health Scenarios: Relationship to EOL Values Before (Block 1) and After (Block 2) Entry of Living Will Responses, AdJUSTING FOR SOCIODEMOgRAPHIC CHARACTERISTICS

\begin{tabular}{|c|c|c|c|c|c|c|c|c|c|}
\hline & \multicolumn{6}{|c|}{ Block 1} & \multicolumn{3}{|c|}{ Block 2} \\
\hline & Age & Race $^{\mathrm{a}}$ & Gender & $\begin{array}{l}\text { Economic } \\
\text { difficulty }^{\mathrm{b}}\end{array}$ & Factor $1^{\mathrm{c}}$ & Factor $2^{\mathrm{d}}$ & Factor $1^{\mathrm{C}}$ & Factor $2^{\mathrm{d}}$ & Living will \\
\hline As you are now & $.18^{* *}$ & 0 & $.21^{* *}$ & .02 & -.10 & $.34 * * *$ & -.09 & $-.33^{* * *}$ & -.080 \\
\hline Alzheimer's Disease & -.03 & $.22 * *$ & $.20 *$ & $-.18^{* *}$ & $-.03^{*}$ & $.32 * * *$ & -.09 & $.29 * * *$ & $-.265 * * *$ \\
\hline Short of breath & -.08 & .03 & $.18^{* *}$ & .09 & $-.15^{*}$ & $.42 * * *$ & -.12 & $.40 * * *$ & $-.190 * *$ \\
\hline Severe stroke & $-.19 * *$ & -.03 & -.03 & $.17^{*}$ & -.12 & $.21 * *$ & -.05 & $.16^{*}$ & $-.320^{* * *}$ \\
\hline Moderate stroke & $-.14^{*}$ & .05 & $.13^{*}$ & $.15^{*}$ & $-.14^{*}$ & $.35 * * *$ & -.11 & $.33 * * *$ & $-.210^{* *}$ \\
\hline Cancer, no pain & -.09 & -.01 & -.04 & .13 & $-.18 * *$ & $.33 * * *$ & $-.15^{*}$ & $.31 * * *$ & $-.230^{* *}$ \\
\hline Cancer with pain & $-.13^{*}$ & -.03 & -.08 & $.18^{* *}$ & $-.22 * *$ & $.34^{* * *}$ & $-.18^{* *}$ & $.31^{* * *}$ & $-.280^{* * *}$ \\
\hline $\begin{array}{l}{ }^{*} p<.05 . \\
{ }_{* *} p<.01 . \\
{ }^{* *} p<.0001 . \\
{ }^{\mathrm{a} C} \text { Coded white or non } \\
{ }^{\mathrm{b}} \text { Scale: } 0=\text { not at all } \\
{ }^{\mathrm{c}} \text { Factor } 1 \text { values: wis }\end{array}$ & $\begin{array}{l}\text { iite. } \\
\text { icult, } 1= \\
\text { for dig }\end{array}$ & $\begin{array}{l}\text { lot very } \\
\text { ty, to a }\end{array}$ & $\begin{array}{l}\text { ifficult, } 2 \\
\text { id pain, }\end{array}$ & d to avoid & $\begin{array}{l}\text { icult, } 3=v \\
\text { cdening ot }\end{array}$ & difficult. & & & \\
\hline
\end{tabular}


values were essentially unchanged in block 2 , these regression coefficients were not repeated in the table for that block.

Among the sociodemographic characteristics, race, age, gender, and financial difficulty were related to treatment preferences in the directions described in previous research: Nonwhites tended to prefer more life-prolonging treatment, but the association was significant only in the Alzheimer's disease scenario. Older individuals tended to want less lifeprolonging treatment, with the association attaining significance in the "as now," severe and moderate stroke, and cancer with pain scenarios. Women preferred less life-prolonging treatment than did men, significant in the "as now," Alzheimer's disease, shortness of breath, and moderate stroke scenarios. Individuals reporting greater financial difficulty preferred significantly more life-prolonging care in the scenarios involving Alzheimer's disease, moderate and severe stroke, and cancer with pain (see Table 3).

\section{Discussion}

Findings provide clear answers to the three questions posed earlier. First, concerning whether EOL values are useful guides to EOL treatment preferences, the answer is in the affirmative: Both value factors predicted treatment preferences independently of each other and demographic characteristics. The religion/longevity/family wishes values predicted treatment wishes in all scenarios; dignity/pain/burden values predicted treatment wishes in most scenarios, excluding only the extremes. The second question was whether EOL values are better predictors than a standard living will would be. We found that only religion/longevity, family wishes values contributed unique variance over and above the living will responses, whereas dignity/pain/burden values seemed redundant with the living will responses (as block 2 of the regression models showed). The answer to the third question, Are some values better predictors than others? is that wishes for longevity and for following the teachings of one's religion and family preferences are more robust predictors of treatment preferences than dignity, pain, and burden-related values. Thus, knowing an individual's values regarding religion, longevity, and following family wishes may be helpful in predicting the EOL care he or she would prefer in most EOL scenarios, over and above preferences expressed in a living will or sociodemographic characteristics. Therefore, these values would be useful additions to an advance care planning document to guide medical care decision making.

\section{Limitations and directions for future research}

The present sample may not have been representative of elders, in that Roman Catholics were probably underrepresented, and the sample may have been more educated than the population. Future research on advance care planning should make a particular effort to reach out to Catholics and less well-educated elders. Another limitation concerns the standard living will question that we used, a very simple question that hardly seems adequate to capture patients' treatment preferences. Yet this is the standard question used in many states, although they often include follow-up questions about whether the patient would prefer specific treatments, e.g., receiving blood. Furthermore, despite the question's simplicity and seeming inadequacy, responses to it did predict treatment preferences to a considerable extent, as did the dignity/pain/burden values.
The life support preferences questionnaire (LSPQ)-based questions, used in the present study as the outcome variables, were hypothetical questions for EOL treatment. These were more detailed and specific than the standard living will questions. Overall, the best outcome variable would be actual treatment preferences in diverse health scenarios elicited from patients approaching the end of life. Future research should explore these issues using data from seriously ill patients, for whom these questions are less hypothetical.

\section{Conclusions}

Regarding the importance of a values history in the absence of a standard living will, EOL values, both factors, may be useful guides to patients' EOL treatment preferences. Regarding their importance in addition to a living will, only the religion, longevity, and family wishes values predicted patient preferences independently of the living will responses; the dignity, pain, and burden values seemed redundant together with the living will responses.

Although increasing numbers of Americans now complete advance care planning documents, ${ }^{4}$ many still do not. For some individuals a values-based advance care planning document may be more acceptable than a standard living will. In such cases, a values history could be a valuable source of information to direct care in the event of decisional incapacitation, as long as the values history touches on issues regarding religiosity, family wishes, and wishes for longevity.

\section{Author Disclosure Statement}

No competing financial interests exist.

\section{References}

1. Omnibus Budget Reconciliation Act of 1990, Public Law No. 101-508;1990.

2. Fagerlin A, Schneider CE: Enough: The failure of the living will. Hastings Cent Rep 2004;34:30-42.

3. Teno JM, Gruneir A, Schwartz Z, Nanda A, Wetle T: Association between advance directives and quality of end-of-life care: A national study. J Am Geriatr Soc 2007;55(2):189-194.

4. Silveira MJ, Kim SY, Langa KM: Advance directives and outcomes of surrogate decision making before death. N Engl J Med 2010;362(13):1211-1218.

5. Teno JM, Licks S, Lynn J, Wenger N, Connors AF, Phillips RS, O'Connor MA, et al.: Do advance directives provide instructions that direct care? SUPPORT Investigators Study to Understand Prognoses and Preferences for Outcomes and Risks of Treatment. J Am Geriatr Soc 1997;45:508-512.

6. Winter L, Parks SM: Ask a different question, get a different answer: Why living wills are poor guides to care preferences at the end of life. J Palliat Med 2010(13):567-572.

7. Christakis NA: Death foretold: Prophecy and prognosis in medical care. Chicago: University of Chicago Press, 1999.

8. Fried TR, Byers AL, Gall WT, Van Ness PH, Towle VR, O'Leary JR, Dubin J: Prospective study of health status preferences and changes in preferences over time in older adults. Arch Intern Med 2006;166:890-895.

9. Winter L, Parker B: Current health and preferences for lifeprolonging treatments: An application of Prospect Theory to end-of-life decision making. Soc Sci Med 2007;65:1695-1707.

10. Prendergast TJ: Advance care planning: Pitfalls, progress, promise. Crit Care Med 2001;29:N34-N39. 
11. Singer PA, Siegler M: Advancing the cause of advance directives. Arch Intern Med 1992;152:22-24.

12. Aging with Dignity. Five Wishes. www.Agingwithdignity .org/forms/5wishes.pdf. (Last accessed February 18, 2013.)

13. Caring Community. End of Life Values-Choices Checklist. www.caringcommunity.org/advance-care-planning/end-oflife-values-chrices-checklist. (Last accessed February 18, 2013.)

14. Doukas DJ, McCullough LA: The values history: The evaluation of the patient's values and advance directives. J Fam Pract 1991;32:145-153.

15. Bookwala J, Coppola KM, Fagerlin A, Ditto PH, Danks JH, Smucker WD: Gender differences in older adults' preferences for life-sustaining medical treatments and end-of-life values. Death Stud 2001;25:127-149.

16. Hare J, Pratt C, Nelson C: Agreement between patients and their self-selected surrogates on difficult medical decision. Arch Intern Med 1992;152:1049-1054.

17. Sehgal A, Galbraith A, Chesney M, Schoenfeld P, Charles G, Lo B: How strictly do dialysis patients want their advance directives followed? JAMA 1992;267:59-63.

18. Zweibel NR, Cassel CK: Treatment choices at the end of life: A comparison of decisions of older patients and their physician-selected proxies. Gerontologist 1989;29:615-621.

19. Singer PA, Martin DK, Kelner M: Quality end-of-life care. JAMA 1999;281:163-168.

20. Aries P: The Hour of Our Death. New York: Oxford University Press, 1981.

21. Steinhauser KE, Christakis NA, Clipp EC, McNeilly M, McIntyre L, Tulsky JA: Factors considered important at the end of life by patients, family, physicians, and other care providers. JAMA 2000;284:2476-2482.

22. Steinhauser KE, Clipp EC, Bosworth HB, McNeilly M, Christakis NA, Voils CI, Tulsky JA: Measuring quality of life at the end of life: Validation of the QUAL-E. Palliat Support Care 2004;2:3-14.

23. Steinhauser KE, Bosworth HB, Clipp EC, McNeilly M, Christakis N., Parker J, Tulsky JA: Initial assessment of a new instrument to measure quality of life at the end of life. J Palliat Med 2002;5:829-841.

\section{Appendix A: Life-Sustaining Treatments and EOL Health Scenarios}

\section{Four treatments}

Antibiotics: Doctors use these medicines to treat serious infections (like pneumonia). Without antibiotics, serious infections can cause life-threatening complications or death.

Cardiopulmonary Resuscitation: Doctors use cardiopulmonary resuscitation (CPR) when a person's heart stops beating or a person stops breathing. Doctors press on the chest to help pump blood, and use artificial breathing. Artificial breathing means the doctor puts a tube in the windpipe. Then a machine breathes for the patient through the tube. Patients usually get medicine by vein. Patients often need an electrical shock to help restart the heartbeat. Without CPR the heart will not start beating again, and the patient will die.

Gall Bladder Surgery: Doctors use surgery to remove the gall bladder when it is inflamed and infected. If untreated, an inflamed and infected gall bladder can rupture and cause lifethreatening complications or death.

Artificial Feeding and Fluids: Doctors use artificial feeding and fluids when people are unable to take enough food and water to stay alive. The food goes through a feeding tube.
24. Downey L, Curtis JR, Lafferty WE, Herten JR, Engelberg RA: The Quality of Dying and Death (QODD) Questionnaire: Empirical domains and theoretical perspectives. J Pain Symptom Manage 2010;39:9.

25. Doukas DJ, Antonucci T, Gorenflo DW: A Multigenerational study on the correlation of values and advance directives. Ethics Behav 1992;2:51-59.

26. Doukas DJ, Gorenflo DW: Analyzing the values history: An evaluation of patient medical values and advance directives. J Clin Ethics 1993;4:41-45.

27. McPherson CJ, Wilson KG, Murray MA: Feeling like a burden to others: A systematic review focusing on the end of life. Palliat Med 2007;21:115-128.

28. Cousineau N, McDowell I, Hotz S, Hebert P: Measuring chronic patients' feelings of being a burden to their caregivers: Development and preliminary validation of a scale. Med Care 2003;41:110-118.

29. Coppola KM, Bookwala J, Ditto PH, Lockhart L K, Danks J H, Smucker WD: Elderly adults' preferences for life-sustaining treatments: The role of impairment, prognosis, and pain. Death Stud 1999;23:617-634.

30. Katz S, Ford AB, Moskowitz RW, Jackson BA, Jaffe MW: Studies of illness in the aged: The index of ADL: A standardized measure of biological and psychosocial function. JAMA 1963;185:914-919.

31. Lawton MP, Brody EM: Assessment of older people: Selfmaintaining and instrumental activities of daily living. Gerontologist 1969;9:179-186.

32. Andresen EM, Malmgren JA, Carter WB, Patrick DL: Screening for depression in well older adults: Evaluation of a short form of the CES-D (Center for Epidemiological Studies Depression Scale). Am J Prev Med 1994;10:77-84.

33. Roccaforte WH, Burke WJ, Bayer BL, Wengel SP: Validation of a telephone version of the Mini-Mental State Examination. J Am Geriatr Soc 1992;4:697-702.

34. Nunnally J, Bernstein ICH: Psychometric Theory. New York: McGraw-Hill, 1994.

35. Kaufman S: And a Time to Die: How American Hospitals Shape the End of Life. New York: Scribner, 2005.

Usually the feeding tube is inserted into the stomach through the left side of the abdomen during surgery. The stomach is stitched closed around the tube. Without the treatment patients die within 7-10 days.

\section{Seven health scenarios}

1. You are in your current state of health.

2. Alzheimer's Disease: You have trouble remembering things and thinking clearly. You cannot recognize people you know, make decisions for yourself, or communicate. You have no chance of recovery. Your mental abilities may get worse quickly or may stay the way they are now for a long time. Your physical condition and abilities are unaffected.

3. Constant shortness of breath as result of a condition such as congestive heart failure, emphysema, or chronic obstructive pulmonary disease (COPD). You are unable to climb stairs or walk more than a few feet. Your medical condition cannot improve. Your condition may get worse very quickly or slowly decline over several years. Your ability to think, reason, and remember is unaffected. 
4. Severe Stroke: You have suffered a severe stroke and have been in a coma for six weeks. In the opinion of the doctor you have no chance for regaining awareness. Your current physical condition is stable but will slowly decline over time. You rely on others for help with feeding, bathing, dressing, and toileting. You may live in this condition for several years.

5. Moderately Severe Stroke. One arm and leg are paralyzed. You have trouble speaking and trouble understanding when others speak. You rely on others for help with feeding, dressing, bathing, and toileting. In the opinion of your doctor you have a very slight chance of improvement.

6. Colon cancer that has spread to the liver, no pain: You are tired and weak. Your thinking and memory are unaffected. You are not in pain. In the opinion of your doctor you have no chance of recovery. Your doctor estimates that you have about six months to live.

7. Colon cancer that has spread to the liver, with pain: You are tired and weak. Your thinking and memory are unaffected. You have pain that requires the constant use of medication. In the opinion of your doctor you have no chance of recovery. Your doctor estimates that you have about six months to live.

\section{Sample question}

You have Alzheimer's disease. You have trouble remembering things and thinking clearly. You cannot recognize people you know, make decisions for yourself, or communicate. You have no chance of recovery. Your mental abilities may get worse quickly or may stay the way they are now for a long time. Your physical condition and abilities are unaffected.

If you developed a serious infection, like pneumonia, would you want to use antibiotics to treat the infection?

\begin{tabular}{|c|c|c|c|c|c|c|}
\hline $\begin{array}{l}\text { Definitely } \\
\text { do not } \\
\text { want }\end{array}$ & $\begin{array}{c}\text { Probably } \\
\text { do not } \\
\text { want }\end{array}$ & Unsure & $\begin{array}{c}\text { Probably } \\
\text { want }\end{array}$ & $\begin{array}{c}\text { Definitely } \\
\text { want }\end{array}$ & $N A$ & Refused \\
\hline $0($ ) & 1() & 2() & 3() & 4() & -2() & -4() \\
\hline
\end{tabular}

NA, not applicable; Refused, refused to answer.

\section{Appendix B: End-of-Life Values Scale \\ Instructions}

I have some questions about things you may think about when you make treatment decisions for yourself. I will ask about several types of things that people often consider and ask you to rate how important each one is in your thinking, on a 0 to 5 scale. " 0 " means "not at all important" and " 5 " means "extremely important."

How important is/are

1. your religious or spiritual beliefs?

2. your wish to have a dignified death?

3. your wish to be spared pain?

4. your wish to avoid burdening family and friends emotionally?

5. your wish to avoid burdening others financially?

6. your wish to avoid being dependent on others?

7. the wishes of other family members regarding your care?

8. your wish to live as long as possible?

Address correspondence to: Laraine Winter, PhD Philadelphia VA Medical Center 3800 Woodland Avenue Philadelphia, PA 19104

E-mail: Laraine.winter@gmail.com 